\title{
DO PROBLEMA DA ALTERIDADE NO PENSAMENTO FREUDIANO: UMA CONSTRUÇÃO*
}

Jacqueline de Oliveira Moreira

Doutora em

psicologia, PUC-SP; mestre em filosofia, UFMG; professora da PUC-MG/ Betim; psicóloga clínica.
RESUMO: Procura-se refletir sobre o tema da alteridade em Freud, pensando as relações do autor com o pensamento greco-romano e a tradição judaica. Objetiva-se, ainda, construir algumas figuras de al teridade, capturar os diferentes graus de comparecimento do Outro que podem ser pensados como causas do sujeito. A partir da leitura dos artigos técnicos de Freud, busca-se apreender as diferentes figuras de alteridade que atravessam a teoria e a clínica freudianas. Palavras-chave: Alteridade; freudismo; sujeito.

ABSTRACT: The problem of alterity in the Freudian thinking: a construction. This article aims at reflecting on the theme of alterity in Freud studying the relations of the author with the Greek-Roman and Jewish tradition. The purpose also is to construct some figures of alterity, catching the different degrees of the presence of the "other", that can be thought of as causes of the subject. From the reading of technical articles we have tried to understand the different figures (Gestalten) of alterity that the Freudian theory and clinic face.

Keywords: Alterity, Freudianism, subject.

$\mathrm{O}_{\mathrm{e}}$ problema da alteridade não se apresenta de modo explícito e claramente tematizado no texto freudiano, pois a obra de Freud é relativamente tributária da lógica identitária presente no pensamento ocidental, ou seja, os paradigmas grego e romano exercem grande fascínio sobre o psicanalista. Atenas e Roma ${ }^{1}$ são as cidades que habitam os sonhos de Freud; o seu

\footnotetext{
*Trabal ho baseado em tese acadêmica: "Figuras de al teridade no pensamento freudiano", 2003. 262 p. Tese. (Doutorado em Psicologia Clínica). Pontifícia Universidade Católica de São Paulo. (Orientador: Luís Cláudio Mendonça Figueiredo.)

${ }^{1} 0$ tema sobre a relação de Freud com Atenas, Roma e Jerusalém será mais trabal hado adiante.
} 
desejo de ser reconhecido pelo mundo ocidental o conduz ao berço dessa cultura. Mas a tradição presente na trama edípica de Freud é a judaica, nesse caso, a cidade de Jerusalém será inscrita no inconsciente de Freud, mas a humilhação a que é submetido o povo judaico, incluindo-se aí a de seu pai, Jacob Freud, leva o na direção de Atenas e Roma. 0 tema da alteridade é fundamental na tradição judaica, e está expresso na figura de Deus, a alteridade por excelência, enquanto que o pensamento greco-romano prioriza ${ }^{2}$ a lógica da identidade. Assim, a problemática da alteridade, em conseqüência da relação ambígua de Freud com 0 judaísmo, aparece implícita em seus textos.

Não podemos negar a ambigüidade freudiana em relação ao judaísmo, no entanto, ao final do texto "As resistências à psicanálise" (1924/1974), Freud chega a declarar que a nova teoria exige um grau de aptidão e aceitação da "situação de oposição solitária - situação com a qual ninguém está mais familiarizado do que um judeu" (FREUD, 1925, p.275). Na interpretação de Fuks (2000), no ato de aproximar a psicanálise do judaísmo, Freud não se limita a ressaltar a condição de solidão teórica e histórica em que vive, mas se refere, também, à condição de estrangeiridade, de sustentação da alteridade e da diferença, marcas comuns do judaísmo e da psicanálise. Sobretudo se pensarmos que a psicanálise se situa historicamente no campo da filosofia da consciência. Fuks segue em sua interpretação, aproximando a experiência da Diáspora judaica, definida como dispersão, como ruptura, com os pacientes da psicanálise que se encontram divididos no " 'país do Outro' aquele que está além de toda fronteira: o inconsciente" (FUKS, 2000, p.48).

Corroborando a lógica identitária inaugurada na Grécia, o pensamento moderno irá afirmar de modo inequívoco, desde a instauração do Cogito Cartesiano, a primazia do eu. Assim, para muitos autores, o conjunto do pensamento moderno pôde ser interpretado como incluído no que se denominou "paradigma da filosofia do sujeito e da consciência". No entanto, embora possa parecer paradoxal, Freud colocou-se como um crítico vigoroso do consciencialismo filosófico que caracteriza esse paradigma do pensamento moderno. Não obstante, Freud não explicita as implicações e os pressupostos de suas teorias e, assim, não desenvolve tematicamente a questão da alteridade.

Foi exatamente essa não-explicitação que nos estimulou a abordar a obra freudiana sob tal prisma. A partir da leitura de alguns textos de Emmanuel Lévinas (1980), o tema da "alteridade" pareceu-nos um legítimo operador conceitual,

\footnotetext{
2 Parece-nos pertinente ressaltar que o verbo 'prioriza' abre espaço para a afirmação de que encontramos no pensamento greco-romano, e até mesmo no moderno, discussões e reflexões sobre o tema da alteridade. Uma modalidade de pensamento não domina hegemonicamente em uma determinada época; o movimento histórico é produzido pela ação do conflito entre vertentes diferentes.
} 
que permitiria uma leitura renovada do texto freudiano, um novo ângulo de leitura que nos daria instrumentos para explorar questões pertinentes tanto para a teoria quanto para a clínica.

Acreditamos que a mais relevante discussão levinasiana sobre a "Problemática daAlteridade" esteja na reflexão de inspiração bíblica sobre Deus enquanto figura negativa de uma "Alteridade Radical" . A discussão situa-se no campo da teologia apofática ou negativa, segundo a qual, sendo absolutamente transcendente, Deus não pode ser racional mente conhecido e apreendido numa trama conceitual. N essa perspectiva, a"Alteridade Radical" não poderia se colocar em contraposição a uma "identidade Originária" pois, enquanto radical, por princípio, não poderíamos defini-la, e esta é uma exigência primordial do pensamento levinasiano.

Entretanto, a idéial levinasiana de "Alteridade" pode ser também tomada como uma categoria fil osófica, ou seja, como um predicado fundamental (praedicamentum), como um modo fundamental de ser da realidade, uma dimensão necessária para que possamos compreender a realidade. Assim concebida, a categoria de "Alteridade" nos ajuda a demarcar um campo discursivo e a estabelecer os contornos de um universo teórico, de um saber que se diferencia e se relaciona.

Nossa proposta visa demonstrar que, ao nos aproximarmos do texto freudiano a partir dessa categoria de "Alteridade", pode ser evidenciado um aspecto de sua originalidade, como texto fundante de um saber inovador e sui generis. Isto é, à luz da categoria de "Alteridade", a psicanálise - enquanto saber que toma como objeto o "inconsciente" - pode ser interpretada como instauração de um novo campo discursivo que escapa à lógica identitária que em geral preside a constituição da racionalidade científica. 0 "inconsciente", tomado como o "objeto" por excelência da psicanálise, seria compreendido, em seu estatuto originário, como uma dimensão da "Alteridade".

Nesse sentido, nossa aproximação com o pensamento de Lévinas se inscreve como uma motivação inicial, embora não tenhamos a pretensão de realizar maior aproximação entre o pensamento levinasiano e o freudiano.

Nossa intenção consiste, portanto, em retomar o texto freudiano, porém não apenas para reiterar mais uma vez as suas idéias, mas para abordá-lo a partir de uma perspectiva que Ihe seja simultaneamente estranha e familiar (Unheimlich/ Heimlich), isto é, o horizonte da alteridade. Acreditamos que essa perspectiva possibilitará o estabelecimento de novas articulações conceituais, tanto em nível da teoria pura (metapsicologia) quanto em nível da clínica.

Ora, podemos desenvolver uma longa argumentação, explicitando a relevância teórica de se realizar uma leitura dos textos freudianos a partir da problemática da alteridade. 0 contexto cultural e filosófico no qual Freud escreveu estava dominado pelo que denominaríamos a problemática da "Identidade" . 0 deslocamento de uma problemática para outra poderá não apenas mediar e desvelar as 
dimensões alteritárias subjacentes às intrincadas tramas psicopatológicas investigadas por Freud na constituição da subjetividade, como, também, revelar as vicissitudes da alteridade no interior da reflexão sobre a cultura.

A obra freudiana foi produzida num contexto filosófico em que predominava o pensamento da identidade e do 'mesmo' e, neste sentido, a temática da diferença e da alteridade não poderia ser plenamente explicitada por suas teorias, uma vez que estas se formam num outro horizonte teórico. No entanto, as diversas épocas da história do pensamento ocidental não podem ser definidas como se fossem "blocos monolíticos" e, assim, embora uma determinada problemá tica teórica goze de hegemonia, isso não significa que nela não circulem, ainda que de modo marginal e pouco elaborado, outros temas, idéias e intuições que só mais tarde serão trabal hados de maneira intensiva. Assim, um autor, ainda que não os elabore intencionalmente e não os tematize de modo claro, poderá trazêlos de modo implícito e obscuro ou até mesmo como uma perspectiva inerente à lógica de seu discurso. Essa investigação, na linha daquilo que não é formulado de modo claro na obra dos pensadores verdadeiramente eminentes, tem se mostrado uma abordagem hermenêutica fecunda e, portanto, nos autoriza a supor que, no caso do texto freudiano, ainda que a problemática da alteridade não apareça como uma preocupação central do autor, pode oferecer-nos uma possibilidade de leitura enriquecedora, tanto para a discussão teórica quanto para a prática clínica.

Talvez a ausência de expressões como "outro" e "alteridade" possa traduzir a tendência solipsista que caracteriza o paradigma da consciência que domina 0 pensamento moderno. Segundo Schneider, o movimento de "edificar uma barreira entre si e o outro, entre o sujeito e objeto, domina não somente a tendência fundamental da filosofia clássica, tendência questionada por Lévinas; mas também é discernível no interior da trajetória freudiana" (SCHNEIDER, 1997, p.71). ParaAssoun, seria mérito de Lacan a introdução da problemática da "Alteridade" no interior da psicanálise, pois Freud promove uma "explosão do outro num discurso que faz da ciência sua única legitimidade semântica" (ASSOUN, 1997, p.98). Fuks, em sua leitura do texto de Assoun sobre a questão da alteridade na psicanálise, reforça nossa posição. A autora revela:

"Pode-se concordar com Assoun quando ele diz que Freud não teve a necessidade, na produção de sua teoria, de designar uma instância discursiva do Outro, mas é preciso contrapor que nem por isso deixou de atrelar a psicanálise à presença da inquietante estranheza: o próprio descentramento do 'saber do inconsciente' e de sua condição de possibilidade, a pulsão, instalou o lugar inexpugnável da alteridade no campo psicanalítico." (FUKS, 2000, p.67) 
Segundo Assoun, Lacan se opõe "ao egologismo identitário que ameaça o destino do 'freudismo', mesmo ao preço de se introduzir uma instância discursiva do 'Outro' que o próprio Freud não sentia de fato como necessária” (ASSOUN, 1997, p.92).

Birman, atento à ambigüidade presente no texto freudiano, anuncia duas diferentes versões de leitura que relacionam a psicologia com a problemática filoidentificação, irá se impondo no discurso freudiano a exigência de uma dimensão ética, pois a presença traumática do outro na constituição da subjetividade implica no reconhecimento de uma dívida simbólica.

ParaBirman, a "introdução ao narcisismo" coloca a problemática da alteridade na cena analítica, mas o autor ressalva que será com o conceito de pulsão que a dimensão al teritária aparecerá de maneira decisiva. As reflexões sobre a alteridade remetem-nos ao universo do pulsional, universo no qual a presença e/ ou ausência do "outro" aparece como fundamental para a economia libidinal do "eu", pois a constituição do "eu" é possibilitada exatamente através da oferenda do "outro". A presença do "outro" é condição de possibilidade da constituição do "eu", o que não implica, porém, na aceitação de um humanismo adocicado, na defesa de uma harmonia preestabelecida, pois o que caracteriza o discurso psicanalítico é o reconhecimento do caráter traumático dessa presença constitutiva do outro. Assim, para Birman, teríamos no texto freudiano uma crescente problematização da perspectiva da alteridade. Segundo ele:

“...0 sujeito em psicanálise seria marcado pela alteridade, marca constitutiva do seu ser [ ...] se o sujeito se constitui pela costura entre o corpo pulsional e o Outro, num movimento sempre recomeçado e insistente, ele é atravessado pela alteridade". (BIRMAN, 1996, p.62).

Mezan pensa a questão da alteridade, centrando a discussão na concepção crítica freudiana acerca da cultura. Revela que o "outro" aparece em "quatro posições possíveis: ou é objeto da pulsão, ou um meio de obter este objeto, ou um obstáculo que se interpõe entre este e o sujeito, ou, por fim, um modelo para o sujeito" (MEZAN, 1985, p.454). 0 autor não irá se dedicar às modalidade que se referem à esfera do objeto; pois o seu objetivo é refletir sobre a forma em que o "outro" mantém sua alteridade na relação de constituição do "eu". 0 tema da identificação, como uma modalidades originária na relação entre eu e o outro, e as dificuldades impostas por essa afirmação constituem o terreno fértil onde irão florescer as reflexões de Mezan sobre a alteridade.

As interpretações de Assoun, Schneider, Birman e Mezan acerca da alteridade parecem-nos muito ricas e representam um horizonte a partir do qual poderemos desenvolver as nossas próprias interpretações. No entanto, pretendemos 
desvelar outras dimensões de alteridade e, com este propósito, tomamos como inspiração a afirmação de Horus Vital Brazil, que assinala:

"a multiplicidade dos objetos-causa do desejo inconsciente, que, embora finitos, apontam, na sua diversidade, para as múltiplas configurações da alteridade dos sujeitos na dimensão fenomênica. Esta estrutura diacrítica e alteritária impõe a concepção de um Outro como um complexo sêmico, com múltiplas derivações semânticas, 0 que é uma questão da fenomenologia." (BRAZIL, 1998, p.166)

A descrição fenomenológica das figuras de alteridade revela-nos várias formas de presença do outro, que pretendemos construir.

\section{ALTERIDADE E JUDAÍSMO: A HERANÇA PATERNA}

Flem, ao pesquisa para 0 homem Freud: 0 romance do inconsciente, traduz as angústias de um conquistador entreAtenas, Roma ejerusalém. 0 filho de Jacob identifica-se e sofre com a humilhação do pai. É preciso que seus agressores se curvem diante do gênio judeu, resgatando, assim, a imagem de seu pai. 0 filho, através da grandiosidade de sua obra, vinga a humilhação paterna, mas o preço parece ser um afastamento da herança paterna e uma aproximação com a cultura dos agressores. Em texto escrito a Roback, Freud declara que Jerusalém é sua parte de incultura, seu continente negro, esquecido em nome da necessidade de filiação com a cultura greco-latina. Freud se filia à cultura ocidental através da vertente greco-romana, buscando reconhecimento intelectual. Segundo ainda Flem, "a Jerusalém invisível para a qual Freud não tem conteúdo nem palavras, esclarece-se pelo ol har que el e dedica a Roma eAtenas. São esses os espelhos de sua identidade" (FLEM, 1993, p.75).

Jerusalém é invisível e silenciosa, mas sua força é inegável. Freud vive no seio de uma contradição intransponível. Roma e a tradição helênica se opõem ao judaísmo. Corroborando essa hipótese de um Freud entre Roma e a tradição judaica, podemos citar um sonho do mestre, no qual ele é levado a uma colina e vê Roma velada pela neblina. Esse sonho remonta à idéia da terra prometida, é Canaã que aparece no subtexto. Nas palavras de Fuks, "o aparecimento deste significante Roma-Canaã, efeito da lógica do sonho, é por si mesmo revelador que dispensa interpretações" (FUKS, 2000, p.34). "Sonhos desse estilo parecemnos resultantes do conflito de ser pai de uma obra ocidental e filho de um pai judeu" (FLEM, 1993, p.90).

A família de Freud é originária da Galícia Oriental, e integra o grupo denominado Ostjuden, judeus orientais que, segundo Fuks:

"Os Ostjuden, de hábitos extremamente conservadores, além de serem pobres, exerciam ofícios menos apreciados socialmente: por tudo isso eram marginalizados pelos 
judeus de fala alemã. É provável que Jakob eAmalie tenham sofrido alguma discriminação ao se instalarem na parte proletária e miserável do bairro judeu..." (FUKS, 2000, p.18)

Esse conflito interno produz efeitos na obra de Freud. Como admirador de Roma eAtenas, a lógica da identidade será resguardada, mas como filho do judaísmo, a dimensão da alteridade se fará presente. Freud não tematiza de forma explícita a dimensão da alteridade. Parece-nos que a dimensão do Outro irá se afirmando em silêncio no movimento da obra de Freud. Seria preciso assumir explicitamente a tradição judaica para que o outro aparecesse sem véu. Segundo Badiou, será o movimento de assumir o judaísmo que permitirá a Lévinas 0 reconhecimento da Alteridade como ponto de partida. Para Lévinas, a origem grega da metafísica subordinou o pensamento à lógica do Mesmo que desconhece 0 outro. É preciso, pois, buscar uma origem que anuncie a anterioridade ontológica do outro. Nas palavras de Badiou:

“É preciso portanto girar o pensamento em direção a uma origem diferente, uma origem não grega, que propõe uma abertura radical e primeira ao Outro, ontologicamente anterior à construção da identidade. É natradição judaica que Lévinas encontra o ponto de apoio para esse giro." (BADIOU, 1995, p.34)

Assim, pretendemos compreender a posição de Freud sobre o tema da alteridade como resultado do seu conflito entre duas fortes tradições, a grecoromana e a judaica. Freud tem como ponto de apoio a origem grega, mas a presença silenciosa de Jerusalém produz efeitos, e a problemática da alteridade aparece ainda que recoberta pelo véu da lógica grega.

Não pretendemos psicanalisar Freud; estamos atentos à advertência de Fuks, que, estudando com cuidado al guns textos que refletem sobre a relação de Freud com o judaísmo, percebe a tentação e conseqüente incursão dos autores na operação de submeter Freud à psicanálise. Fuks cita Mezan, em sua crítica contundente a esse tipo de abordagem: a psicanálise não é de modo algum 'retorno do reprimido'(FUKS, 2000). Devemos ter cuidado para não cair em tal falácia. A nossa reflexão descreve a prioridade do tema da al teridade na cultura judaica e as ambigüidades de Freud em relação a essa herança e, como conseqüência, em relação à questão da alteridade. Freud não tematiza o tema de forma explícita, não encontramos nenhum texto intitulado "O problema da alteridade", mas a problemática atravessa todo o pensamento de Freud: não seria esse duplo fenômeno resultante da relação de Freud com o judaísmo?

A interpretação que Freud faz de si mesmo na carta aberta a Romain Rolland, intitulada "Um distúrbio de memória naAcrópole", revela o conflito interno do 
pai da psicanálise entre duas grandes tradições. Freud tenta compreender o seu mal-estar e a sensação de incredulidade diante daAcrópole. Ele e seu irmão estavam em Roma e surge a possibilidade de ir a Atenas, mas não seria permitido desembarcar na Grécia sem passaportes. Qual seria o passaporte de entrada? Para poder ingressar no mundo ocidental, ser reconhecido como grande pensador, seria necessário negar o "Pai"? Freud anuncia a sua divisão: um Freud judeu, um Freud ocidental. Parece que a impossibilidade infantil pensada por Freud em ver Atenas é uma expressão do receio de que seja impossível a vitória, ou seja: como poderá um filho de um judeu conquistar Atenas? Freud confirma nossa hipótese ao convidar para sua argumentação a idéia dos arrasados pelo sucesso. 0 sofredor não se permite a felicidade: a frustração interna ordena-lhe que se aferre à frustração externa. A frustração interna é a materialização do severo superego, e este, por sua vez, é o representante da herança paterna, no caso de Freud, da tradição judaica que foi humilhada e torturada pela cultura greco-romana. Freud revela que duvidava de que um dia chegaria tão longe, e o desejo adolescente de viajar estava vinculado à insatisfação com a casa e a família. A vergonha de ser judeu coloca Atenas e Roma nos sonhos de Freud, mas a herança paterna produz um mal-estar diante das cidades. Freud anuncia:

"Pode ser que um sentimento de culpa estivesse vinculado à satisfação de havermos realizado tanto: havia nessa conexão algo de errado, que desde os primeiros tempos tinha sido proibido. Era relacionado com as críticas da criança ao pai [...] Parece como se a essência do êxito consistiria em ter realizado mais do que o pai realizou [...] Assim, o que interferia em nossa satisfação de viajar aAtenas era um sentimento de respeito filial." (FREUD, 1936, p.245)

0 filho realizou mais do que o pai, mas a que preço? Foi reconhecido por aqueles que humilharam sua família e tradição, está no centro da cidade-berço da cultura ocidental e é reconhecido como um grande pensador, mas o preço foi negar seu pai e o judaísmo. Diante daAcrópole, Freud vive a experiência psíquica de desrealização e fracasso.

Entretanto, cabe uma ressalva: a relação de Freud com o pai é muito mais complexa, pois Jacob Freud se filia ao grupo dos judeus iluministas, buscando uma aceitação pela comunidade. A Bíblia de Philippson, adotada pelo pai, é presenteada a Freud com a dedicatória que anuncia o desejo de que o filho se torne o novo judeu do iluminismo. ${ }^{3}$ o próprio Jacob aproxima Freud da corrente

\footnotetext{
${ }^{3}$ Ver em Rizzuto, 2001, quando a autora investiga os caminhos biográficos da descrença de Freud em Deus, trabalhando extensamente sobre a relação de Freud com o pai e conseqüentemente sua relação com o judaísmo.
} 
ocidental, mas sua origem ortodoxa marcou toda a família com o signo da miséria e do fracasso; só Freud venceu. Talvez nesse momento, Freud tenha se distanciado do judaísmo e se aproximado de Atenas e Roma. A estratégia do pai funcionou para aproximar o filho do iluminismo, mas não o aproximou do judaísmo.

Desta forma, as relações ambíguas de Freud com a tradição judaica parecemnos uma fonte de compreensão para a ausência explícita da palavra alteridade, e, concomitantemente, representa uma forma de compreensão para a presença implícita do tema da alteridade na constituição do sujeito. Jerusalém é a cidade que atravessa a trama edípica de Freud, mas sua decepção com o pai o coloca na trilha de Atenas e Roma; contudo, as marcas edipianas não desaparecem.

Parece-nos pertinente refletir por que a tradição judaica evoca o tema da alteridade. Derrida, na reconstrução de Fuks, revela que "a identidade do Judeu consigo mesmo talvez não exista". Judeu seria o outro nome dessa impossibilidade de ele ser ele próprio. Fuks acrescenta: "a judeidade sobressai como um dos nomes do não-idêntico" (FUKS, 2000, p.76). A ausência de uma pátria coloca 0 povo judeu na situação de nômade e, por conseqüência, de permanente estrangeiridade. Segundo Fuks, o guia de leitura de Freud em M oisés e o monotésmo é a precedência do nomadismo e da errância sobre a sedentarização na história do povo judeu, colocando, pois, a estrangeiridade como valor supremo. Fazer do profeta do judaísmo, Móises, um estrangeiro, um egípcio, está em perfeita consonância com o princípio do judaísmo, a saber, o princípio da estrangeiridade, da diferença, daquilo que escapa. É interessante notar que Freud nos "Estudos autobiográficos" (1925) ressalta a condição de errância de sua família, acentuando, pois, a prevalência da estrangeiridade sobre a identidade na sua história pessoal.

Reafirmando a situação de estrangeiridade, podemos falar sobre a transcendência absoluta de YHVH, anunciando a presença que se define por uma ausência. 0 tetragrama é impronunciável e, portanto, escapa à representação, colocando como ponto de partida para o thos judaico a questão da alteridade radical. Fuks busca na leitura de Lévinas sobre o Deus judaico elementos para compreender a dimensão de alteridade constitutiva do povo judeu. Reproduzimos, pois, as passagens do texto de Fuks que se dedicam à leitura do termo Kadosh. Segundo a autora, a leitura de Lévinas sobre o termo hebraico aplicado a Deus, Kadosh, se traduz por santo. Do ponto de vista etimológico, 'santo' significa 'separado', 'a inscrição de nome de Deus seria a inscrição originária da diferença'. Kadosh designa a al teri dade radicalmente separada e dessacralizada, isto é, sem conteúdo, sem objeto e sem forma aderida, transcendente até à Ausência. E porque habita fora do espaço e mais longe que o tempo, o santo será sempre 0 Estrangeiro dos estrangeiros. Assim, a estranheza do Deus judaico é absolutamente conforme à estranheza de seu povo. 
Acreditamos que a religião judaica acentua a questão da alteridade porque a experiência da Diáspora, do êxodo, a prevalência do nomadismo e da errância e, ainda, a experiência de um Deus que se apresenta como pura ausência, pura diferença, conflita com a idéia de identidade; anuncia a prevalência daAlteridade sobre a identidade.

A reflexão sobre o problema da Alteridade em Freud através da sua relação com o judaísmo parece-nos fascinante, mas não corresponde diretamente ao objetivo proposto nesse texto, a saber, refletir sobre a incidência da alteridade no interior da obra freudiana.

\section{AS DIFERENTES FIGURAS DE ALTERIDADE:} AS CATEGORIAS DO DISCURSO

Na primeira página de "A pulsão e suas vicissitudes” (1915), Freud anuncia alguns pressupostos epistemológicos da psicanálise. 0 autor defende a tese de que a atividade científica consiste primordialmente "na descrição dos fenômenos" (FREUD, 1915, p.137). Freud revela que a psicanálise difere da filosofia, pois a última parte de conceitos básicos e procura apreender todo o universo. Ao contrário, a psicanálise "se atém aos fatos de seu campo de estudo, procura resolver os problemas imediatos da observação, sonda o caminho à frente com o auxílio da experiência" (FREUD, 1923, p.323). Confirmando essa tese no texto "Sobre o narcisismo: U ma introdução" (1914/ 1974), Freud aconselha o psicanalista a não abandonar a observação pela especulação, porque nas bases de uma teoria especulativa teremos conceitos nebulosos, enquanto que uma ciência é erigida a partir da "interpretação empírica" (FREUD, 1914, p.93). Frente aos desafios da explicação dos fenômenos clínicos, Freud revela que é uma grande tentação adentrar o universo da especulação, "feita sob o patrocínio de uma escola filosófica, [...] mas nenhum substituto pode satisfazer os requisitos da ciência" (FREUD, 1919, p.133).

Todavia, a relação de Freud com a filosofia é marcada por uma certa ambigüidade epistemológica: por vezes Freud opõe a prática científica da clínica ao mundo fantástico da especulação, posicionando-se a favor da prática científica baseada na observação; em contrapartida, continuando na primeira página de "As pulsões e suas vicissitudes" (1915), Freud revela que, apesar de uma ciência emergir a partir de uma série de fatos empíricos, muitas vezes ela implica a utilização de idéias abstratas que não são retiradas da observação, e que são tais idéias que se tornarão os conceitos fundamentais (Grundbegriffe) de uma ciência. A querela em torno da ambigüidade epistemológica de Freud é um tema que já foi discutido por comentadores consagrados como, por exemplo, Paul-LaurentAssoun (1983). Aqui, interessa-nos em especial a colocação freudiana sobre a importância do psicanalista não distanciar-se da experiência clínica, pois é nela que se encontra a base empírica de sua ciência. 
Seguindo esse conselho, gostaríamos de focalizar nossa reflexão sobre o problema da alteridade no pensamento freudiano a partir de considerações sobre a teoria da clínica, ou melhor, de ponderações técnicas.

Freud inicia uma de suas recomendações sobre a técnica da psicanálise convocando a arte do ensino do jogo de xadrez, tomando-a como uma metáfora para a compreensão do ensino da arte da psicanálise.

"Todo aquele que espere aprender o nobre jogo do xadrez nos livros, cedo descobrirá que somente as aberturas e os finais de jogos admitem uma apresentação sistemática exaustiva e que a infinita variedade de jogadas que se desenvolvem após a abertura desafia qualquer descrição desse tipo. Esta lacuna na instrução só pode ser preenchida por um estudo diligente dos jogos travados pelos mestres." (FREUD, 1913, p.164)

A idéia subjacente a esta afirmação de que o aprendizado deve contemplar o "estudo diligente dos jogos travados pelos mestres" parece-nos revelar que 0 lugar mais apropriado para saber sobre a técnica e a práxis da psicanálise não é 0 livro, mas sim a experiência clínica mesma; sobretudo aquela estabelecida no seu próprio processo analítico. Pois será o movimento no interior do próprio processo de análise que anunciará a complexidade das noções de transferência e repetição, que são conceitos fundamentais da clínica psicanalítica.

0 conceito de transferência é discutido no artigo técnico "A dinâmica da transferência" (1912). Nele, Freud parte do pressuposto de que a "combinação entre disposição inata e influências sofridas durante os primeiros anos produz um método específico de conduzir a vida erótica", que ele nomeia "clichês estereotípicos". Esses clichês são constantemente repetidos, de modo que a aproximação em direção a uma nova pessoa é acompanhada de idéias e ações predeterminadas pela história dos laços libidinais do sujeito. Uma parcela desse histórico de catexias libidinais volta-se para a figura do analista. 0 cliente inclui 0 analista num circuito psíquico de laços libidinais que remontam à sua história edípica. Nesse sentido, a transferência será concebida como uma verdadeira condição de possibilidade para o processo analítico e introduz a dinâmica da relação eu / outro como uma possibilidade de reflexão e direção para os destinos do circuito pulsional do sujeito em análise. A noção de transferência exige, no mínimo, como é óbvio, a presença de dois termos a existência de um eu e um outro. A compreensão da dialética eu/ outro no processo analítico está condicionada à posição a partir da qual se busca a reflexão: a perspectiva do cliente difere da dimensão do analista.

As repetições de processos mórbidos e conflitivos na vida e, freqüentemente, processos que são desencadeados ou agravados por contingências existenciais 
conduzem o sujeito à busca de uma ajuda especializada. Ao procurar uma análise, o sujeito, sem muita clareza, demanda intervenções de um outro-abstrato que se torna a expressão de saber sobre ele que ele mesmo não possui.

Esta teoria científica, encarnada pelo analista, possibilitaria compreender os fenômenos humanos, através de conceitos abstratos que permitem categorizar e analisar os fatos que efetivamente se realizam na realidade da vivência empírica, que é sempre particular. Toda produção de conceitos é uma abstração da realidade imediata, ou seja, é uma forma de mediatização entre a vivência em si e a compreensão do sujeito. 0 homem busca formas alteritárias que possam tornar compreensível sua vivência. Os mitos, as religiões e as ciências representam "alteridades" na forma de sabedorias que organizam, fornecem sentido e compreensibilidade às experiências humanas. A psicanálise integra esse grupo que nomeamos como "alteridades abstratas", que possi bilita aos sujeitos, através de uma forma de saber, uma possível compreensão sobre a sua vivência. Parecenos importante enfatizar que esta figura de alteridade que denominamos "outro-abstrato" refere-se, em linhas gerais, a uma construção simbólica que oferece ordenação para a experiência concreta. No caso, os mitos, religiões e ciências exercem função de outro-abstrato que por vezes são utilizados como forma defensiva diante da verdade primeira - a verdade da castração - que é condição de possibilidade dessas formas. Parece paradoxal, as grandes formas simbólicas criadas pela humanidade surgem para promulgar a lei simbólica constitutiva da vida humana, mas são utilizadas como forma de defesa contra essa ordem maior. Assim, podemos encontrar dois níveis de outro-abstrato: os mitos, religiões e ciências exercem a função de outro-abstrato, de formas universais que permitem a compreensão da condição humana e a lei da castração, que se apresenta como o outro-abstrato, que determina todas as nossas construções, seria o ponto zero da existência. N esse momento, cabe uma interrogação ética sobre a prática do analista. Seria função ética do analista promulgar a lei da castração sem tréguas? Ou seria a busca de um termo médio entre o desvelamento dessa verdade básica e formas de suportá-la? Essa é uma questão que deve ser respondida por cada um em sua clínica.

Retomada nossa construção das figuras de alteridade, convidamos Mezan para auxiliar na compreensão da relação eu/ outro no processo terapêutico. De acordo com M ezan, "o analista tem a ocasião de fazer precisamente aquilo que, segundo Foucault, é o processo de criação de uma ética: elaborar uma relação de si a si que permita a ele constituir-se como sujeito moral" (MEZAN, 1998, p.206). Não se trata apenas de o cliente se perguntar sobre sua repetição e pensar em uma modal idade diferencial de repetição. Trata-se, especialmente, da ação do analista em manter a condição de escuta, de não cair nas gratificações narcísicas ofertadas pelo cliente através da lógica de um outro-transferencial. 0 cliente se relaciona 
com o analista, depositando nele suas imagos e desejos inconscientes; não vê a pessoa do analista, pois é prisioneiro da transferência. No processo psicanalítico, o outro participa nos processos transferenciais como migrações clandestinas dos desejos inconscientes.

Freud enfatiza o encontro entre o cliente e a "alteridade do saber", representada pela função do analista, quando revela que no processo analítico não ocorre um encontro entre dois sujeitos num sentido meramente dialógico. Não se trata do diálogo entre dois sujeitos e nem, muito menos, de um encontro entre sujeito e objeto, como prescreve a clássica teoria do conhecimento. Segundo Freud, o analista " deve simplesmente escutar e não se preocupar se está se lembrando de alguma coisa" (FREUD, 1912, p.150). Não se trata de uma busca de conhecimento lógico ou de uma teoria prévia e formalmente explícita sobre a experiência do cliente, pois o analista ouve de um outro lugar. Entretanto, o anal ista não deve escutar apenas a partir da trama de sua subjetivação, não deve ouvir simplesmente como um outro concreto, mas deve encarnar, na sua função, o "outroabstrato" do saber psicanalítico. De acordo com Freud, o analista "deve ser opaco aos seus pacientes e, como um espelho, não mostrar-Ihes nada, exceto o que lhe é mostrado" (FREUD, 1912, p.157). 0 analista deve evitar a manifestação desmedida de sua pessoa, deve ser uma presença discreta e não ocupar o lugar de um outro próximo ao cliente. Freud adverte que os psicanalistas jovens e ávidos ficarão tentados a colocar sua própria individualidade livremente no debate; 0 princípio subjacente a essa atitude seria a idéia da reciprocidade, da simetria, que os levaria a trocar uma confissão por outra. Nas relações psicanalíticas, esse tipo de técnica pode induzir, ainda no início do processo, o surgimento de barreiras ou resistências inconscientes; pois não podemos esquecer que 0 analista é introduzido no circuito de repetições libidinais do cliente. Freud recomenda aos analistas uma " frieza emocional que cria condições vantajosas para ambas as partes: para o médico, uma proteção desejável para sua própria vida emocional, e, para o paciente, o maior auxílio que lhe podemos hoje dar" (FREUD, 1912, p.153).

Em suas recomendações (1913), quando Freud sugere a seleção de pacientes, algum leitor desavisado poderia pensar que a decisão de aceitar ou não um cliente depende exclusivamente da simpatia do analista pelo candidato à análise. Dessa forma, na seleção de clientes, estaria presente de maneira decisiva a individualidade do psicanalista. Mas Freud esclarece que "esteve-se apenas empreendendo uma 'sondagem', a fim de conhecer o caso e decidir se ele é apropriado para psicanálise" (FREUD, 1913, p.165).

0 fator determinante da escolha se refere às condições fundamentais impostas pela teoria e práxis da psicanálise, ou seja, é o "outro-abstrato" que anuncia os critérios de seleção. Basicamente , o cliente para a psicanálise é aquele que está disponível, em princípio, para estabelecer uma "neurose de transferência". 
Assim, o sujeito, ao buscar um processo analítico, não visa um encontro entre amigos, um encontro intersubjetivo mas, de modo mais ou menos explícito, a sua visada é a dimensão de "alteridade do saber"; e o analista de sua parte não deve desfilar sua individualidade, não deve apresentar-se como um outro concreto. Muitas vezes, o conhecimento da vida do analista por parte do cliente pode ser algo doloroso e até mesmo negado. Alguns clientes espantam-se ao encontrar 0 analista comendo um sanduíche, e existem casos de clientes que só percebem a gravidez da analista quando esta anuncia a sua saída para o parto.

Mas estaríamos defendendo a tese de um analista desencarnado, com total ausência de sua dimensão de outro? Não é possível despojar-se totalmente da individualidade e, mais, a ética da psicanálise exige o reconhecimento da castra ção, por isso o analista não deve persistir fixado em uma dimensão de "outroabstrato". Não podemos elevar uma função, ainda que essencial ao processo analítico, a uma realidade hegemônica em nome da qual seria anulado a concretude do encontro entre analista e analisando.

Assim, o analista aparece, também, como um "outro concreto", mas não só a partir de sua individualidade intencional e consciente. Freud observa que 0 analista "deve voltar seu próprio inconsciente, como um órgão receptor, na direção do inconsciente transmissor do paciente" (FREUD, 1912, p.154). No processo analítico, ocorreria um encontro entre dois inconscientes, ou seja, entre dois elementos alteritários - na medida que o inconsciente é também um "outro" em relação à identidade egóica tanto do analista como do analisando. Essa figura de alteridade não deve ser tomada, entretanto, num sentido estritamente abstra to, pois a manifestação do inconsciente refere-se sempre a um Outro do próprio eu, e carrega as marcas da história concreta e simbólica do sujeito. 0 inconsciente pode ser denominado de modo pleonástico, em contraposição ao "outroabstrato", como um "outro-alteritário" ou, para simplificar a expressão, poderemos designá-lo apenas através de uma forma substantivada, como o "alteritário".

0 analista, através do seu inconsciente, aparece como um outro que visa 0 encontro com o outro que habita o eu do cliente, a saber, o inconsciente do cliente. Mas essa dimensão de outro presente no encontro entre inconscientes refere-se ao encontro com o "estranho familiar". Preso à sua identidade, ao seu eu, 0 analista não poderia captar o inconsciente do cliente. 0 cliente busca 0 mesmo, uma certa identidade no encontro com 0 analista, mas este, na sua função de "outro-abstrato" e na sua escuta atravessada pelo seu próprio alteritário, cria a possibilidade do des-encontro, do vazio, do silêncio e, assim, estabelece as condições para a emergência do alteritário do cliente. Calligaris ilustra, através de um exemplo cotidiano, que "a procura comum quando se fala é a procura de uma tampa, ou seja, que o discurso esteja entre dois semelhantes" (CALLIGARIS, 1989, p.31), mas quando não se encontra com uma tampa, não se encontra com 
o semelhante, pode-se ter presente uma formação inconsciente no lugar do vazio do des-encontro. Vejamos o exemplo:

“Você entra num táxi e fala com o motorista: 'Puxa que frio!'. Você está esperando que o motorista responda: 'É mesmo!'. Estamos com dois semelhantes insatisfeitos com o frio... [...] Se o motorista não responde, você vai procurar outro semelhante. [...] [...] talvez ele queira me assaltar. Isto daria 0 assaltado e 0 assaltante, que formam outro casal de semelhantes. Mas se você não encontrar um semelhante... Eventualmente vai aparecer no que você falou, um efeito de sujeito. Por exemplo, apesar do frio você irá esquecer seu casaco, produzir um ato falho. Enfim, qualquer tipo de formação inconsciente." (CALLIGARIS, 1989, p.32)

U ma cliente contou-me um episódio em que um rapaz perguntou se ela conhecia a cidade de Tiradentes. Ela respondeu que não. Ele disse, então, que aquela era uma ótima cidade para casais de namorados. Algum tempo depois, ela relatou seu carnaval na cidade de Diamantina, com a expectativa de que eu, a sua analista, iria intervir no conteúdo de seu relato, falar algo sobre as suas atuações durante o carnaval. Mas eu, simplesmente, a interroguei: "Não era em Tiradentes?" e a cliente respondeu de modo inesperado: "Eu já des-esperei". Em seguida começou a rir e disse: "Eu queria dizer que já havia deixado de esperar, mas na verdade estou mesmo desesperada." 0 que me pareceu interessante é que a ausência de um semelhante para a fala referente aos acontecimentos em Diamantina produziu um ato falho. É na possibilidade do des-encontro do diálogo simétrico que a dimensão inconsciente do cliente emerge. Quando o analista escuta, sem se preocupar com a sucessão lógica dos fatos, quando ele volta seu inconsciente como uma antena parabólica na direção da transmissão inconsciente do cliente, ele cria um hiante ou uma vacância que possibilita o surgimento do diferente, do "estranho familiar", do alteritário.

Assim, além da presença do "outro-abstrato" do saber, em sua função terapêutica, o psicanalista trabalha, também, a partir da posição de um outro do eu, ou seja, especificamente a partir de seu inconsciente, daquilo que designamos como o seu "alteritário".

Existe ainda, no entanto, uma presença diferente que introduz uma nova dimensão de Outro. 0 cliente coloca 0 analista em uma posição que se refere a um "outro transferencial" . 0 analista é convocado, através da transferência, a ocupar o lugar de outro próximo, o que alude à trama libidinal do cliente. 0 cliente faz coincidir com a figura do psicanalista seus protótipos de laços infantis. Não se trata da individualidade do analista, o cliente o percebe como um outro próximo, mas essa proximidade não se restringe ao aqui-e-agora do encontro com 0 analista, mas recua no tempo e revela uma trama libidinal arcaica. No encontro 
transferencial entre eu e outro, entre cliente e analista não está em questão 0 analista como um outro-pessoa, ou seja, na sua individualidade. Na transferência, o analista é convidado a ocupar um lugar de outro, mas referente aos jogos inconscientes do cliente. 0 cliente projeta no analista as figuras de outros, convocando outros próximos à sua rede libidinal para atuar na transferência. A pessoa do analista é substituída por uma outra pessoa próxima à história libidinal do cliente. Freud pondera que:

“...esta catexia recorrerá a protótipos, ligar-se-á a um dos clichês estereotípicos que se acham presentes no indivíduo; ou para colocar a situação de outra maneira, a catexia incluirá o médico numa das séries psíquicas que o paciente formou. Se a 'imago paterna' foi o fato decisivo no caso, o resultado concordará com as relações reais do indivíduo com o seu médico." (FREUD, 1912, p.134)

Freud descreve dois tipos básicos de transferência: a transferência positiva e a negativa. Na primeira, podemos encontrar a presença de sentimentos amistosos conscientes e o prolongamento de impulsos eróticos recalcados. A transferência positiva mais a segunda modalidade de transferência, a negativa, trabalham para a resistência. $\mathrm{Na}$ transferência de conteúdos inconscientes, Freud anuncia que:

"Os impulsos inconscientes não desejam ser recordados da maneira pela qual o tratamento quer que o sejam, mas esforçam-se por reproduzir-se de acordo com a atemporalidade do inconsciente e sua capacidade de alucinação. Tal como acontece nos sonhos, o paciente encara os produtos do despertar de seus impul sos inconscientes como contemporâneos e reais; procura colocar suas paixões em ação sem levar em conta a situação real." (FREUD, 1912, p.143)

Trata-se, aqui, da questão do amor transferencial, quando o cliente opera uma sobreposição do "outro-transferencial" sobre o "outro-pessoa" do analista. Segundo Freud, o cliente está "expressando uma resistência, sob o disfarce de estar enamorado" (FREUD, 1915, p.217), apaixonado pelo analista. Assim, parece-nos que, na resistência, um dos artifícios utilizados é a superposição entre "outro-transferencial" e "outro-pessoa". 0 cliente confunde fantasmaticamente suas imagos inconscientes com a pessoa concreta do analista. Desta forma, a presença do outro-pessoa, ainda que seja em nível fantasmático, trabalha no sentido da resistência, do boicote ao trabalho da análise. Na transferência negativa, por exemplo, a agressividade é dirigida para a pessoa do analista, no entanto 0 verdadeiro alvo da hostilidade é o "outro-transferencial" , o outro referente às imagos inconscientes. Mas o cliente, tanto no amor transferencial, quanto na transferência negativa, acredita de forma veemente que o objeto do seu amor ou 
de sua hostilidade é a pessoa do analista. Para a resistência, o cliente convoca o "outro-pessoa" do analista, porém, é claro que não se trata da individualidade do analista, mas da fantasia do cliente sobre a pessoa do anal ista, uma vez que esta é sobreposta às imagos inconscientes transferenciais.

Parece-nos interessante ressaltar que, no processo terapêutico, o analista aparece como um objeto que suscita a transferência. 0 termo objeto introduz uma nova modalidade de reflexão sobre a presença do outro no processo analítico. Freud revela, ao tratar da questão da dinâmica da transferência, que:

"Originalmente, conhecemos apenas objetos sexuais, e a psicanálise demonstra-nos que pessoas que em nossa vida real são simplesmente admiradas ou respeitadas podem ainda ser objetos sexuais para nosso inconsciente." (FREUD, 1912, p.140)

0 cliente, no momento em que convoca, para a sua resistência, a presença do psicanalista na modalidade de "outro-pessoa", ainda que desconsiderando, na verdade, a individual idade do analista, o está colocando na posição de "outro-objeto", de instrumento para a repetição dos seus laços libidinais inconscientes. A posição de "outro-objeto" parece-nos ser aquela que mais nega a dimensão de alteridade, de diferença, ou seja, que visa estabelecer um encontro com o idêntico. Mas a operação resvala e anuncia o diferente através do "outro-transferencial". N este sentido, o manejo da transferência é decisivo, pois o analista se retira do lugar de outro-objeto, de alvo direto do amor ou do ódio, e anuncia a imago inconsciente, o "outro-transferencial" que diz do desejo e produz um efeito de sujeito. É importante enfatizar que todo analista, enquanto profissional, se coloca no lugar de outro-objeto para o cliente, se oferece para a manifestação da transferência.

0 "outro-objeto" parece-nos, no interior da teoria psicanalítica, um importante grau de manifestação da alteridade, pois o inconsciente visa o objeto de satisfação no encontro com o "outro-pessoa". Busca-se o objeto perdido, causa do desejo e, conseqüentemente, do sujeito, pois o sujeito não é a causa de si mesmo, apenas pode advir a partir do outro. Sendo que este outro se apresenta para o inconsciente na forma de objeto de satisfação, teorizado na mitíca "Vivência de satisfação". Freud define desejo, no "Projeto" (1895), como o movimento de investimento no traço de memória, buscando a vivência alucinatória da primeira e mítica experiência de satisfação. Desejo é, pois, busca do objeto perdido que foi oferecido pelo outro como uma resposta ao desamparo do infans. Nesse sentido, o outro é anterior ao eu e condição de possibilidade de sua existência biológica e simbólica. Na relação com o "outro-pessoa" busca-se o "outro-objeto", objeto da pulsão, da experiência de satisfação, objeto perdido.

Por fim, impõe-se ainda mencionar a figura de alteridade presente na teoria do narcisismo, pois, para a psicanálise, o sujeito advém do outro, da relação com 
outro, sendo que essa relação é atravessada pela problemática do narcisismo. o "outro-narcísico" representaria uma diferente modalidade de manifestação de alteridade. 0 "outro-narcísico" não tem o estatuto de uma alteridade abstrata, pois é preciso a presença concreta do outro no processo de constituição do eu; mas não é simplesmente uma outra pessoa, na medida que aparece na trama de constituição da subjeti vidade como uma marca fantasmática, um traço imaginário. Podemos aventar a hipótese de que, no narcisismo primário, 0 outro precisa encarnar a perspectiva da pessoa próxima, mas anunciando sempre a dimensão imaginária. Enquanto que, no narcisi smo secundário, que coloca a questão do vínculo cultural, o "outro-pessoa" privilegia a dimensão do "outro-abstrato".

Assim, a partir da leitura hermenêutica dos ArtigosTécnicos, quando provocamos o texto com o tema da alteridade, construímos seis figuras de alteridade, ou seis graus de manifestações da al teridade, que podem ser ordenadas em uma escala decrescente de radicalidade. Sendo que a máxima presença de alteridade, no nosso esquema, situa-se no "outro-abstrato", traduzida pela verdade da castração e em seguida pelas formas universais de saber. A segunda forma refere-se ao "outro-pessoa", importante elemento nas discussões éticas, mas que guarda certa estranheza em relação à psicanálise. 0 "outro-alteritário" representa a terceira manifestação da alteridade; trata-se de uma modalidade que combina dimensões abstratas ou simbólicas com a experiência do sujeito. 0 "outrotransferencial" aparece como quarta forma de alteridade, que também combina dimensões concretas e simbólicas, pois depende da presença de uma outra pessoa para desencadear o processo de transferência. Na quinta figura, teremos 0 "outro-narcísico", que aparece como uma exigência interna da teoria psicanalítica, mais precisamente da teoria sobre a constituição da subjetividade. Se o eu ou o "outro-pessoa" éo pal co de manifestação de todas as dimensões de alteridade, o "outro-narcísico", por sua vez, atravessa todas as relações, na medida que ele é condição de possibilidade do eu, do "outro-pessoa", do sujeito. Enfim, descrevemos uma sexta modalidade de alteridade: 0 outro-objeto enquanto dispositivo propulsor do desejo.

Essas diferentes figuras de alteridade podem apontar para uma escala de afirmação ou negação da presença do outro, não esquecendo que, em última instância, a alteridade não pode ser negada, pois apresenta-se como um limite intransponível, para usar a expressão freudiana, como um rochedo da castração. A dimensão de alteridade expressa na figura do "outro-abstrato" é recusada na psicose e renegada na perversão, mas a Lei, o limite, reaparece e se impõe no sintoma, introduzindo uma perspectiva mortífera para o sujeito. 0 mecanismo de recusa e/ ou renegação do outro-abstrato traz diversas conseqüências para a relação entre 0 eu e as figuras de alteridade. 
A categoria de alteridade se impõe como um complexo sêmico de múltiplas derivações semânticas, exigindo uma descrição fenomenológica para capturar os diferentes graus de comparecimento do outro; sendo que essas diversas figuras de alteridade podem ser pensadas como causas do sujeito, ou seja, o sujeito emerge a partir da incidência do outro. E essas figuras podem ser utilizadas em leituras clínicas ou teóricas da psicanálise.

Recebido em 4/ 4/ 2003. Aprovado em 29/ 8/ 2003.

\section{REFERÊNCIAS}

ASSOUN, P-L. (1978) Freud, filosofia efilósofos. Rio de Janeiro: Francisco Alves. (1983) Introdução à epistemologia freudiana. Rio de Janei ro: Imago. (1997) "O sujeito e o outro em Lévinas e Lacan". Cadernos de Subjetividade. v. 5, n.1, São Paulo, Educ, p.91-116.

BADIOU, A. (1995) Ética: um ensaio sobre a consciência do mal. Rio de Janeiro: Relume Dumará.

BIRMAN, J. (1997) Estilo e modernidade em psicanálise. São Paulo: Ed. 34. (1996) "Indeterminismo e incerteza do sujeito na ética da psicanálise (uma leitura sobre o fundamento ético do discurso freudiano)", in FRANÇA, M. I. (org.), Ética, psicanálise e sua transmissão Petrópolis: Vozes.

BRAZIL, H.V. (1998) 0 suje to da dúvida ea retórica do inconsciente. Rio de Janeiro: Imago.

CALLIGARIS, C. (1989) Introdução a uma dinica diferencial da psicose. Porto Alegre: Artes Médicas.

FLEM, L. (1993) 0 homem Freud: 0 romance do inconsciente. Rio de Janeiro: Campus.

FREUD, S. ( 1974) Edição standard brasilèra das obras psicológicas completas, Rio de Janeiro, Imago.

(1950 [1895]) “Projeto para uma psicologia científica", v. I, p.303410.

(1900) "Interpretação dos sonhos", v. IV eV, p.11-611.

(1912) “Dinâmica da transferência”, v. XII, p.131-146.

(1912b) "Recomendações aos médicos que exercem a psicanálise", v. XII, p.147-162.

(1913) "Sobre o início do tratamento", v. XII, p.163-190.

(1915 [1914]) "Observações sobre o amor transferencial", v. XII, p.207221.

(1914 b) "Sobre o narcisismo: uma introdução", v. XIV, p.85-122.

(1915a) "A pulsão e seus destinos", v. XIV, p.129-164.

(1919 [1918]) "Linhas de progresso na terapia psicanalítica”, v. XVII, p.199-214.

(1925 [1924]) “As resistências à psicanálise", v. XIX, p.263-284.

(1925 [1924]) “Um estudo autobiográfico", v. XX, p.13-94. 
(1936) “Um distúrbio de memória na Acrópole”, v. XXII, p.291-306. FUKS, B. (2000) Freud e a judeidade: A vocação do exílio. Rio de Janeiro: Jorge Zahar.

LÉVINAS, E. (1980) Totalidade e infinito. Lisboa: Edições 70.

MEZAN, R. (1998) Tempo de muda: Ensaios de psicanálise. São Paulo: Companhia das Letras. CNPq.

(1985) Freud, pensador da cultura. São Paulo/ Brasília: Brasiliense/

RIZZUTO, Ana M. (2001) Por que Freud rejeitou Deus? São Paulo: Loyola.

SCHNEIDER, M. (1997) "A proximidade em Lévinas e o Nebenmensch freudiano". Cadernos de Subjetividade. n. 1, v. 5, São Paulo, Educ, p.71-90.

Jacqueline de Oliveira M orera

Rua Congonhas, 161 São Pedro

30330-100 Belo Horizonte MG

Tel (31) 3223-3951

jackdrawin@yahoo.com.br 